\title{
Variations
}

Variations Revue internationale de théorie critique

15 | 2011

La haine

\section{La Haine}

\section{(2) OpenEdition \\ 1 Journals}

Édition électronique

URL : http://journals.openedition.org/variations/80

DOI : 10.4000/variations.80

ISSN : 1968-3960

Éditeur

Les amis de Variations

Édition imprimée

Date de publication : 1 mars 2011

\section{Référence électronique}

"La Haine », Variations [En ligne], 15 | 2011, mis en ligne le 01 février 2012, consulté le 22 septembre 2020. URL : http://journals.openedition.org/variations/80 ; DOI : https://doi.org/10.4000/variations.80 


\section{Editorial}

\section{La Haine}

Dans Le livre des passages, Walter Benjamin attire l'attention du lecteur sur la nécessité de se tenir en état d'alerte, il recommande ainsi d'être toujours prêt à sonner l'alarme face aux dangers qui menacent la démocratie.

Attentive à cette recommandation, la revue Variations se propose avec ce numéro de questionner cette passion triste qui, tel un feu, peut s'embraser et hypnotiser les êtres ; mais elle cherche aussi à se constituer en sentinelle.

Car, aujourd'hui, nous nous trouvons dans une situation inédite et complexe. Malgré l'effort acharné d'apparaître sous les traits de la ratio, le système politique et économique mondial, axé sur un néo-libéralisme, ne semble plus tenir aucune promesse pour le vivre-ensemble. Il ne se concentre désormais que dans les politiques d'austérité, de contrôle et de répression, demande toujours plus de soumission et cherche à liquider les formes de solidarité collective qui ont surgi au sortir de la deuxième Guerre Mondiale. Les idées et les partis qui se trouvent à l'extrême-droite de l'échiquier européen connaissent quant à eux une flambée et accompagnent la banalisation des mots d'ordres aussi brefs qu'hargneux qui envahissent l'espace public. Racisme, antisémitisme, homophobie, mystification identitaire croissent dans le sillage des crises économiques et politiques.

Mais les temps connaissent aussi les tiraillements, les tensions et surtout les promesses. En parallèle, tout un chacun peut sentir le souffle de révolte, de refus du monde tel qu'il va, qui des zones dites « périphériques » du Maghreb, du Machrek, de l'Islande, mais aussi étouffé comme en 
Chine par exemple, avance cependant vers le cœur de l'Europe : Grèce, Portugal, Espagne, France. Les systèmes s'érodent, les êtres crient qu'ils veulent autre chose. Certains s'indignent, certains occupent et délibèrent, d'autres lancent des pierres. Un peu partout, un printemps fleurit en quête de justice et d'équité, mais aussi de dignité et d'avenir.

Le numéro, La Haine, voit ainsi le jour dans un moment historique où tout est possible, plein des promesses et des espoirs, mais aussi inquiet des forces archaïques à l'œuvre. Ce numéro a ainsi pour objectif de déconstruire et d'interroger cette passion triste qui brûle tout ce qu'elle touche. La crise globale fait jaillir de vieux discours que nous ne voulons plus entendre, de la bouche d'intellectuels mondains, de journalistes réactionnaires et d'artistes perdus. Nous ne voulons plus entendre : «Vive Le Pen!» (Ménard), «Je comprends Hitler» (von Trier), sans parler des jérémiades zemmouriennes, des élucubrations sarkozystes, de l'amour de philosophes européens pour les théoriciens nazis comme Schmitt, Heidegger ou Jünger, du mépris des essayistes à l'égard des pauvres (Sloterdijk), des juifs et des arabes (Sarrazin). Sans oublier la haine de tous les colons à l'encontre de la révolution démocratique en cours. Ces discours, agressifs, se veulent harmonieux, pour l'ordre, pour l'unité de la nation, du peuple de France, de l'Occident chrétien. Il s'agit de concepts qui veulent écraser la différence et le particulier par leur généralité, comme dirait Adorno. Nous jetons à la figure des adorateurs de l'Identité nationale ce numéro, sûrs de leur infliger une critique intellectuelle inassimilable.

C'est dans l'analyse de cette intersection, entre résurgence des discours réactionnaires et débordements démocratiques, que se situe cette quinzième livraison de Variations, riche de contributions internationales et inédites en langue française. D'un point de vue historique, Frederic Jameson fait retour sur le romancier britannique Wyndham Lewis qui banalisait le fascisme et son ascension dans son essai de 1931. C'est cette banalisation et rationalisation des prises de positions racistes que nous observons en France dans le discours politicien et journalistique qui est dénoncée 
par Hans Horch. Il revient pour nous sur le livre vendu à des millions d'exemplaires de Thilo Sarrazin, politicien social-démocrate allemand et ancien directeur de la Bundesbank, selon lequel l'Allemagne irait à sa perte économique, culturelle et démographique en raison de la seule présence des populations immigrées. Face à ces résurgences réactionnaires, John Holloway nous invite à rompre avec les cercles de la reproduction sociale et économique et à penser une politique qui s'engouffre dans les failles de l'hégémonie du capital. Frédéric Neyrat explore quant à lui l'idée de haine dans la philosophie, l'oppose à la détestation et la ramène à ce qui construit l'existence même. Ce sont ensuite les représentations politiques du peuple que questionne Francis Dupuis-Déri. Celles-ci s'illustrent dans le débat qu'il évoque entre agoraphobie et agoraphilie. Abordant le champ culturel et artistique, Julien Bordier revient sur un événement qui se déroula à l'ombre du film $L a$ Haine : une compilation de musiques inspirées du film, devenue une référence dans le mouvement hip-hop hexagonal. José Chatroussat évoque la manière dont les classes dominantes haïssent le prolétariat. On voit alors comment ce discours haineux construit les rapports sociaux et élabore des représentations du prolétariat comme une entité stable et unifiée. Daniel Veron, quant à lui, renverse la notion en se demandant comment la haine, en tant qu'affect, marque également des moments d'irruptions dans un espace de parole confisqué. A ce titre, il nous invite à lire dans les expressions multiples du refus autant de potentialités politiques. Enfin, Lucia Sagradini illustre la haine exercée par le pouvoir, en revenant pour nous sur la répression qui s'abattit sur l'Argentine à partir de 1976. Une haine exprimée par la junte militaire à l'encontre de toute ouverture des possibles et qui conduisit à la disparition de 30000 personnes.

Le hors-champ de Variations nous propose ensuite un article d'Alexander Neumann sur les conséquences des politiques européennes : une gestion de l'activité salariée qui se caractérise par la vie mutilée que subit le monde du travail. Nicolas Poirier revient quant à lui sur les interventions de Claude Lefort dans la revue Socialisme ou Barbarie, et notamment comment il y développa, loin du 
marxisme orthodoxe, la notion d'expérience prolétarienne.

Pour terminer, Clément Homs et Didier Epsztajn nous présentent deux ouvrages : Crédit à mort de Anselm Jappe, et, Hémisphère gauche de Razmig Keucheyan.

Bonne lecture. 